\title{
DISPONIBILIDADE DE ÁGUA ÀS PLANTAS DE MILHO EM SOLOS DE DIFERENTESTEXTURAS(1)
}

\author{
R. CARLESSO(2) \& R. F. SANTOS(3)
}

\begin{abstract}
RESUMO
O objetivo deste experimento foi avaliar diferenças na quantidade total de água armazenada no solo, na capacidade de armazenamento de água disponível às plantas e no consumo de água de plantas de milho cultivadas em solos de diferentes texturas. $\mathbf{O}$ experimento foi instalado em área do Departamento de Engenharia Rural da Universidade Federal de Santa Maria no ano agrícola 1995/ 1996. Utilizou-se um conjunto de 12 lisímetros de drenagem com dimensões de $156 \mathrm{~cm}$ de comprimento, $100 \mathrm{~cm}$ de largura e $80 \mathrm{~cm}$ de profundidade, protegidos das precipitações por uma cobertura móvel. Os tratamentos consistiram de dois níveis de manejos da água no solo (irrigado e déficit hídrico terminal aplicado durante a fase de crescimento vegetativo) e três texturas de solo (argila pesada, franco-argilo-siltosa e franco-arenosa). Os resultados demonstraram maior capacidade de armazenamento de água disponível às plantas para o solo de textura franco-arenosa $(112 \mathrm{~mm})$ do que para o solo de textura argila pesada $(102 \mathrm{~mm})$ e de textura franco-argilo-siltosa $(94 \mathrm{~mm})$. No entanto, esses valores representam 44, 41 e $77 \%$ da quantidade total de água armazenada nos solos argi la pesada, franco-argilo-si ltosa e franco-arenosa, respectivamente. Para uma mesma profundidade do solo e em condições de déficit hídrico, o solo de textura franco-arenosa apresenta maior capacidade de armazenamento de água disponível às plantas de milho do que os solos de textura argila pesada e francoargilo-siltosa.
\end{abstract}

Termos de indexação: irrigação, déficit hídrico, água no solo, textura do solo

(1) Recebido para publicação em setembro de 1997 e aprovado em setembro de 1998.

(2) Engenheiro-Agrônomo, Professor Titular do Departamento de Engenharia Rural, Centro de Ciências Rurais, Universidade Federal de Santa Maria (UFSM). CEP 97119-900 Santa Maria (RS). Bolsista do CNPq.

(3) Engenheiro-Agrônomo, aluno do curso de Pós-Graduação em Engenharia Agrícola, UFSM. 


\title{
SUMMARY: SOIL WATER AVAILABILITY TO MAIZE PLANTS CULTIVATED IN SOILS WITH DIFFERENT TEXTURES
}

\begin{abstract}
The objectives of this experiment were to identify differences in the total quantity of water stored in soil, storing capacity of water available to the plants and in the water consumption of maize plants cultivated in soils of different textures. The experiment was conducted at the experimental area of the Rural Engineering Department of the Federal University of Santa Maria during the 1995/ 1996 growing season. A set of 12 drainage Iysi meters was used. Thesewere $156 \mathrm{~cm}$ long, $100 \mathrm{~cm}$ wideand $80 \mathrm{~cm}$ deep and wereplaced under a shelter to avoid rainfall. The treatments consisted of two soil water managements (irrigated and terminal soil water deficit applied during vegetative growth) of three soils with distinct textures: dayey, loamy and sandy. A completely randomized statistical design with two replications was used. The results indicated that the soil's water available to the plants was greater in the sandy soil $(112 \mathrm{~mm})$ than in the clayey $(102 \mathrm{~mm})$ and loamy $(94 \mathrm{~mm}$ ) soils. However, these values represented 44,41 and $77 \%$ of the soil's total stored water capacity for the clayey, loamy and sandy soils, respectively. Consi dering a given soil depth, there was a greater availability of water to the mai ze plants for sandy soi Is than for clayey and loamy soils.
\end{abstract}

Index terms: irrigation, water deficit, soil water, soil texture

\section{NTRODUÇÃO}

Muita ênfase tem si do dada para a quantificação do consumo de água pelas plantas nos diferentes subperíodos de desenvolvimento e reduzida importância tem sido conferida à quantificação da lâmina de água disponível e seus efeitos no crescimento e desenvolvimento das plantas de milho. Alguns experimentos realizados associaram o comportamento da cultura em relação ao potencial da água no solo. Entretanto, de maneira geral, o potencial de água relatado não representa as condições de déficit ou excesso de água na profundidade ativa do sistema radicular.

O fluxo da água do sol o para planta e desta para a atmosfera depende da disponibilidade hídrica do solo e da condução da água pel os diferentes órgãos da planta até as folhas, onde ocorre a regulação do fluxo transpiratório. De acordo com Matzenauer \& Sutili (1983), o consumo de água pela cultura depende das condições meteorológicas que determinam a demanda evaporativa da atmosfera, da tensão da água no solo, do solo e das características das plantas, tais como área foliar, sistema radicular e altura da planta.

O déficit hídrico no solo afeta quase todos os processos fisiológicos. Várias revisões bibliográficas fornecem informações detalhadas sobre os seus efeitos em processos fisiológicos específicos (H siao, 1973; Begg \& Turner, 1976; F ischer \& Turner, 1978). Essas revisões abordam diferentes aspectos das alterações fisiológicas nas plantas em resposta a déficits hídricos no solo (Wilson \& Eastin, 1982; Krieg, 1983; Peacoak \& Wilson, 1984).
Nos trabalhos de Denmead \& Shaw (1962), observa-sesignificativa redução na evapotranspiração em plantas de milho quando cerca de $20 \%$ da água disponível foi removida do solo sob condição de evapotranspiração de 5,6 mm dia-1. Sob condiç̧ão de evapotranspiração de 4,1 mm dia-1, a redução de evapotranspiração ocorreu somente quando cerca de $50 \%$ da água disponível foi removida do solo. Dessa forma, verifica-se que existe relação entre a disponibilidade deágua no sol o às plantas, cultura e demanda evaporativa da atmosfera.

Muitos estudos têm demonstrado que, entre espécies ou cultivares, o maior determinante do total de água absorvida do solo é a profundidade de extração (profundidade do perfil do solo explorado pel osistema radicular das plantas) do quea extração que ocorreem cada profundidade, equea quantidade de água absorvida é correlacionada com a produtividade das culturas em condições em que o suprimento de água é limitado (Hurd, 1974; Angus et al., 1983; Ludlow \& Muchow, 1990).

Entretanto, Passioura (1983) questionou a contribuição das raízes mais profundas do perfil na extração de água no solo, porque a produção de carboidratos ocasionada pela absorção de água das camadas profundas do perfil foi inferior à quantidade de carboidratos necessária pela planta para estimular o crescimento dessas raízes. Deacordo com Ludlow \& Muchow (1990), o aumento do déficit hídrico no sol o ocasiona diferenças na distribuiçãoe atividade do sistema radicular, podendo variar a quantidade e a disponibilidade da água para as plantas, conforme a capacidade das plantas em aprofundar ou expandir o sistema radicular aumentando o volume de sol o explorado. 
A capacidade de armazenamento de água disponível às plantas (CAD) e a fração da água disponível (FAD) (razão entre a quantidade atual e a quantidade total de água disponível no solo) são indicadores da duração e intensidade de ocorrência do déficit hídrico (Ritchie et al., 1972; Meyer \& Green, 1980; Carlesso, 1993). Tais indicadores do déficit hídrico possuem vantagens por serem primariamente dependentes da taxa de uso da água e das propriedades físicas do solo (Ritchie et al., 1972; Carlesso, 1995). O déficit hídriconas plantas podeser provocado, de acordo com Ritchie (1981), por uma deficiência no suprimento de água na zona radicular e por uma excessiva demanda evaporativa da atmosfera. Experimentos instalados em solos de diferentes texturas apresentam resultados semelhantes, em condições de deficiência de água no solo, em termos de crescimento e desenvolvimento das plantas. Entretanto, esses resultados são de difícil comparação com os valores de armazenamento de água do solo determinados a partir dos valores de capacidade decampo e ponto demurcha permanente.

Este trabalho teve como objetivo avaliar diferenças na quantidadetotal de água armazenada no solo, na capacidade de armazenamento de água disponível às plantas e no consumo de água de plantas de milho cultivadas em solos de diferentes texturas.

\section{MATERIAL E MÉTODOS}

O experimento foi realizado no ano agrícola 1995/ 1996 em área experimental do Departamento de Engenharia Rural da Universidade Federal deSanta Maria, RS. Utilizaram-se 12 lisímetros de drenagem, constituídos de caixas de cimento amianto de 1.000 litros, com dimensões de $156 \mathrm{~cm}$ de comprimento, $100 \mathrm{~cm}$ de largura e $80 \mathrm{~cm}$ de profundidade. Na parteinferior de cada caixa, foram colocadas tubulações para coletar, separadamente, a água de drenagem. $\mathrm{Na}$ base das caixas, foi col ocada uma camada de 8-10 cm de brita para facilitar a drenagem e, sobre a brita, uma lâmina de material filtrante (Bidim). Os lisímetros foram protegi dos das precipitações por uma estrutura fixa, em arcos, recobertos por uma lona leve que permanecia sob a cobertura somente durante a ocorrência das preci pitações. Ocorreu evaporação direta da água do solo para atmosfera, pois os lisímetros não foram recobertos com material impermeável.

Os solos utilizados foram: (a) Latossolo Roxo distrófico textura argila pesada, coletado em local manejado há, aproxi madamente, 10 anos pelosistema de plantio direto, no município de Santo Ângel o(RS); (b) Podzólico Vermelho-Escuro textura franco-argilosiltosa, coletado em local de campo nativo no município de J úlio de Castilhos (RS), e (c) Podzólico Vermelho-Amarelo textura franco-arenosa, col etado em local de campo nativo no município de Santa Maria (RS). Amostras de material dos solos foram retiradas da camada de $0-20 \mathrm{~cm}$ de profundidade. Anterior à instalação do experimento, foram aplicados oito cicl os de saturação e drenagem no solo do interior dos lisímetros. O delineamento experimental foi ointeiramentecasualizado com dois manejos da água de irrigação (irrigado e déficit hídrico terminal aplicado durante o estádio de desenvolvimento vegetativo, aos 15 dias após a emergência - DAE) e três classes de solo, com duas repetições, perfazendo 12 parcelas experimentais.

A adubação de correção e manutenção baseou-se nos resultados da análise do solo. Na adubação, utilizou-se o equivalentea $3.200 \mathrm{~kg} \mathrm{ha-1}$ de cal cário, $120 \mathrm{~kg} \mathrm{ha}^{-1}$ de N, $20 \mathrm{~kg}$ ha-1 de $\mathrm{P}_{2} \mathrm{O}_{5}$ e $20 \mathrm{~kg} \mathrm{ha}^{-1}$ de $\mathrm{K}_{2} \mathrm{O}$ no solo de textura argila pesada; $13.600 \mathrm{~kg} \mathrm{ha}^{-1}$ de calcário, 140 kg ha-1 de N, 110 kg ha-1 de $\mathrm{P}_{2} \mathrm{O}_{5}$ e $70 \mathrm{~kg} \mathrm{ha}^{-1}$ de $\mathrm{K}_{2} \mathrm{O}$ no solo de textura franco-argilosiltosa e $3.200 \mathrm{~kg} \mathrm{ha}^{-1}$ de cal cário, $160 \mathrm{~kg}$ ha-1 de N, $80 \mathrm{~kg} \mathrm{ha}^{-1}$ de $\mathrm{P}_{2} \mathrm{O}_{5}$ e $70 \mathrm{~kg}$ ha-1 de $\mathrm{K}_{2} \mathrm{O}$ no solo de textura franco-arenosa. O calcário foi aplicado 60 dias antes da semeadura, e a adubação de manutenção foi realizada em linha por ocasião da semeadura. O nitrogênio foi aplicado na linha, utilizando uréia parcelada em três aplicações: na base, aos 30 e 45 DAE.

O experimento foi instalado no dia 23 de fevereiro de 1996, e a emergência ocorreu no dia 27 de fevereiro de 1996. O espaçamento foi de $15 \mathrm{~cm}$ entre plantas e $100 \mathrm{~cm}$ entrelinhas, perfazendo uma população de 66.666 plantas ha-1. A área em volta do experimento foi cultivada com a cultura de milho, proporcionando uma bordadura de, aproximadamente, $500 \mathrm{~m}^{2}$. O desbaste foi realizado aos $5 \mathrm{DAE}$, e a irrigação foi realizada igualmente em todos os lisímetros até $15 \mathrm{DAE}$. Após este período, foram feitas irrigações somente nos tratamentos irrigados. As irrigações foram realizadas manualmente por meio de um regador graduado, sempre que a evapotranspiração máxima acumulada da cultura, determinada pelo método do tanque classe " $\mathrm{A}$ ", atingia $25 \mathrm{~mm}$.

O conteúdo de água no sol o foi determinado por meio de uma sonda denêutrons (CPN, Model 503 DR). Um tubo de acesso ( $50 \mathrm{~mm}$ de diâmetro interno) foi instalado na parte central de cada lisímetro. A calibração da sonda de nêutrons foi realizada antes da instalação do experimento, no próprio local, para cada classe e profundidade do sol o. As leituras foram feitas a cada dois dias com um incremento de profundidade de $20 \mathrm{~cm}$ até a base do lisímetro.

A CAD foi calculada pela diferença entre o conteúdo volumétrico de água no solo no limite superior e no limite inferior de disponibilidade de água às plantas, para cada camada de solo. Considerou-se como limite superior de água disponível às plantas o valor do conteúdo de água no sol o observado após 48 horas de drenagem do solo 
(durante esse período, a superfície do solo dos lisímetros foi recoberta com material impermeável). O solo dos lisímetros foi previamente saturado, aplicando-se uma intensidade de irrigação, por aspersão, superior à capacidade de infiltração de água no solo por um período de aproximadamente 14 horas. Considerou-se comolimiteinferior deágua disponível às plantas o valor do conteúdo de água no solo, determinado quando as plantas estavam completamente senescidas, havendo, assim, a extração de toda a água disponível no solo, segundo Carlesso (1995). A FAD foi obtida, durante o desenvolvimento das plantas, pela razão entre a CAD atual (lâmina deágua disponível às plantas no perfil do solo) ea CAD do solo. A quantidadetotal de água armazenada no solo (QTA) foi avaliada no limite superior de água disponível às plantas, incluindo todas as camadas do lisímetro.

A evapotranspiração da cultura do milho foi determinada segundo a equação do bal anço hídrico. Uma vez queo experimento foi realizadoem lisímetros protegidos das chuvas, os valores da precipitação pluvial e do escoamento superficial foram desconsiderados da equação geral. Os resultados foram submetidos à análise estatística, utilizando-se o programa Statistical Analysis System V6.06. Determinou-se a análise da variância, e médias dos tratamentos foram comparados pelos testes $\mathrm{F}$ e de Tukey a 5\% de probabilidade.

\section{RESULTADOS E DISCUSSÃO}

Embora a cultura tenha sido semeada fora do período recomendado para a região, observou-se que a radiação solar e a temperatura do ar durante a fase reprodutiva das plantas foram suficientes para o bom desenvolvimento da cultura. $\mathrm{O}$ valor médio da temperatura máxima foi adequado, principalmente no período inicial de desenvolvimento das plantas, atingindo oval or de $30,1^{\circ} \mathrm{C}$ em fevereiro. Entretanto, para o Sul do Brasil, de acordo com Cirilo \& Andrade (1994), o atraso na semeadura reduz o rendimento de grãos e decresce o número de grãos por planta (características não avaliadas neste experimento).

No quadro 1, são apresentados os valores do limite inferior, limite superior e CAD para cada tipo e profundidade do solo, bem como a quantidadetotal de água armazenada no perfil do solo. Os valores do limite superior de disponibilidade deágua às plantas foram menores para os três solos na camada superficial (0-20 cm de profundidade) em relaçãoàs demais camadas. Valores semel hantes do limite superior foram observados para os solos de textura argila pesada e franco-argilo-siltosa.

O limite inferior de água disponível às plantas foi semel hante para o solo de textura argila pesada nas três camadas do solo. Um aumento nos valores

Quadro 1. Limite superior e inferior de água disponível às plantas, capacidade de armazenamento de água disponível e quantidade total de água armazenada em três solos de diferentes texturas

\begin{tabular}{|c|c|c|c|}
\hline \multirow{2}{*}{ Variável } & \multicolumn{3}{|c|}{ Textura do solo } \\
\hline & Argila pesada & F ranco-argilo-siltosa & Franco-arenosa \\
\hline & \multicolumn{3}{|c|}{ Camada de $0-20 \mathrm{~cm}$} \\
\hline $\begin{array}{l}\text { Ls }\left(\mathrm{cm}^{3} \mathrm{~cm}^{-3}\right) \\
\text { LI }\left(\mathrm{cm}^{3} \mathrm{~cm}^{-3}\right) \\
\text { CAD }(\mathrm{mm})\end{array}$ & $\begin{array}{l}0,32 \mathrm{a} \\
0,21 \mathrm{a} \\
22 \mathrm{c}\end{array}$ & $\begin{array}{l}0,34 \mathrm{a} \\
0,19 \mathrm{a} \\
30 \mathrm{~b}\end{array}$ & $\begin{array}{l}0,22 \mathrm{~b} \\
0,05 \mathrm{~b} \\
34 \mathrm{a}\end{array}$ \\
\hline CAD $(\mathrm{mm})$ & \multicolumn{3}{|c|}{ Camada de $20-40 \mathrm{~cm}$} \\
\hline $\begin{array}{l}\text { Ls }\left(\mathrm{cm}^{3} \mathrm{~cm}^{-3}\right) \\
\text { LI }\left(\mathrm{cm}^{3} \mathrm{~cm}^{-3}\right) \\
\text { CAD }(\mathrm{mm})\end{array}$ & $\begin{array}{l}0,40 a \\
0,22 a \\
36 a\end{array}$ & $\begin{array}{l}0,39 a \\
0,22 a \\
34 b\end{array}$ & $\begin{array}{l}0,23 b \\
0,06 b \\
34 b\end{array}$ \\
\hline CAD $(\mathrm{mm})$ & \multicolumn{3}{|c|}{ Camada de $40-60 \mathrm{~cm}$} \\
\hline $\begin{array}{l}\text { Ls }\left(\mathrm{cm}^{3} \mathrm{~cm}^{-3}\right) \\
\text { LI }\left(\mathrm{cm}^{3} \mathrm{~cm}^{-3}\right) \\
\text { CAD }(\mathrm{mm})\end{array}$ & $\begin{array}{l}0,44 \mathrm{a} \\
0,22 \mathrm{~b} \\
44 \mathrm{a}\end{array}$ & $\begin{array}{l}0,42 \mathrm{a} \\
0,27 \mathrm{a} \\
30 \mathrm{~b}\end{array}$ & $\begin{array}{l}0,28 b \\
0,06 c \\
44 a\end{array}$ \\
\hline CAD $(\mathrm{mm})$ & \multicolumn{3}{|c|}{ Armazenamento total } \\
\hline $\begin{array}{l}\text { CAD }(\mathrm{mm}) \\
\text { QTA }(\mathrm{mm})\end{array}$ & $\begin{array}{l}102 b \\
232 a\end{array}$ & $\begin{array}{r}94 c \\
230 a\end{array}$ & $\begin{array}{l}112 \mathrm{a} \\
146 \mathrm{~b}\end{array}$ \\
\hline
\end{tabular}

$\mathrm{L}_{\mathrm{S}}=$ Limite superior de água disponível às plantas; $\mathrm{L}_{1}=$ Limite inferior de água disponível às plantas; $C A D=$ capacidade de armazenamento de água disponível às plantas; QTA = Quantidade total de água armazenada no solo no limite superior de água disponível às plantas.

Valores seguidos da mesma letra minúscula, na horizontal, não diferem pelo teste de Tukey $(P \leq 0,05)$. 
do limite inferior de disponibilidade foi observado com o incremento da profundidade no sol o detextura franco-argilo-siltosa. I sto deveu-se, provavel mente, à maior fertilidade e à correção da acidez realizada na camada superficial do solo, condicionando o desenvolvimento do sistema radicular próximo à superfície do solo. Indiferentemente do tipo de textura do solo, observaram-se valores menores do limite inferior na camada superficial do solo em comparação com as camadas mais profundas. Isto deveu-se, basicamente, à evaporação da água diretamente da superfície do solo.

Analisando o limite superior e inferior de disponibilidade, nota-se que o limite superior de disponibilidade no solo de textura franco-arenosa, na camada superficial, foi semelhante aos valores observados para o limite inferior para os solos de textura argila pesada e franco-argilo-siltosa. Além disso, a CAD na camada superficial para o solo de textura franco-arenosa foi de 55 e 13\% superior à CAD dos solos de textura argila pesada e francoargilo-siltosa, respectivamente. Esses resultados evidenciam quea disponi bilidade deágua às plantas é maior na camada superficial do solo de textura franco-arenosa. Na camada de $40-60 \mathrm{~cm}$ de profundidade, o sol o detextura franco-argilo-siltosa apresentou menor lâmina de água disponível que os sol os de textura franco-arenosa e argila pesada.

Em termos de armazenamento total de água, observa-se maior CAD para o solo de textura francoarenosa (112 mm) do que para o solo de textura argila pesada (102 mm) e para o solo de textura franco-argilo-siltosa (94 mm). No entanto, esses valores representam 44, 41 e $77 \%$ da quantidade total deágua armazenada nos solos detextura argila pesada, franco-argilo-siltosa e franco-arenosa, respectivamente. Tais resultados evidenciam que os sol os detextura argila pesada efranco-argil o-siltosa, embora apresentassem aproximadamente $40 \%$ a mais de água total armazenada no perfil do que o sol o de textura franco-arenosa, armazenaram menor CAD do que o solo de textura franco-arenosa. Esses resultados concordam com os de Fiorin et al. (1992) que verificaram que maior capacidade de armazenamento pode não representar maior potencial de água extraível às plantas.

Deacordo com Kiehl (1979), a quantidade deágua armazenada no perfil do solo não-disponível às plantas está relacionada principalmente com as características físicas do solo. A quantidade deágua necessária para envolver as partículas de determinado solo está em função de sua superfície específica que é inversamente proporcional ao diâmetro das partículas, reforçando os resultados da literatura que indicam maior retenção de água em sol os detextura franco-argilo-sil tosa eargila pesada.

Os resultados do quadrado médio da análise da variância, para o período de 15 a $31 \mathrm{DAE}$, obtidos para a quantidadetotal deágua armazenada nosolo, CAD, FAD eevapotranspiração real sãoapresentados no quadro 2. Diferenças significativas entre os níveis de manejo da água para a CAD no solo foram observadas a partir de $29 \mathrm{DAE}$, com val ores de FAD correspondentes a 0,49, 0,70 e 0,45 para os sol os de textura argila pesada, franco-argil o-siltosa efrancoarenosa, respectivamente. Diferenças significativas foram observadas entreas texturas dos sol os para a quantidade total de água armazenada no solo e a FAD durantetodo o período de desenvol vimento das plantas. Plantas submetidas a déficit hídrico terminal apresentaram redução significativa nos valores da FAD no solo em relação aos tratamentos irrigados aos 24 DAE. Não houve interação da textura do solo e nível de manejo da água de irrigação para o armazenamentototal deágua no solo, FAD ea CAD.

O solo de textura argila pesada apresentou, na camada superficial, maior taxa de extração deágua, logo após a suspensão da irrigação (Figura 1). A pós, observou-se maior extração na camada de $20-40 \mathrm{~cm}$ de profundidade e, posteriormente, na camada de 40-60 cm de profundidade. Maior taxa de extração foi observada nas camadas mais profundas do solo devida à maior disponibilidade de água (Quadro 1). Hoogenboom et al. (1987) observaram aumento na taxa de extração de água no solo pelas raízes de plantas de soja abaixo da camada mais seca do perfil. Resultados similares também foram descritos por Blum et al. (1991), para a cultura do sorgo. Aos 58 DAE , praticamentetoda a água disponível nosolo de textura argila pesada tinha sido extraída pelo sistema radicular das plantas.

No solo de textura franco-arenosa, ocorreu redução gradativa na taxa de extração de água no solo, após a aplicação do déficit hídrico, a partir da camada superficial, sem, no entanto, exaurir totalmente a água do solo. Essa pequena taxa de extração observada na camada superficial do solo de textura franco-arenosa possivelmente tenha mantido a viabilidade do sistema radicular nessa camada. Os valores da taxa de extração de água no solo de textura franco-argilo-siltosa apresentaram menor amplitude do que observada para os demais sol os analisados.

$\mathrm{Na}$ figura 2, são apresentados os valores acumulados de extração de água no solo nas três profundidades dos sol os submetidos a déficit hídrico terminal. Praticamente toda a água disponível às plantas foi extraída do sol o pelas plantas cultivadas no solo de textura argila pesada até 30 dias após o início do déficit hídrico (45 DAE, Figuras 1 e 2). A reduzida disponibilidade de água às plantas observada na camada superficial do sol o de textura argila pesada (Quadro 1) podeter sido conseqüência da inviabilização do sistema radicular, possi velmente devido ao rápi do secamento dessa camada associada ao envio de sinais radiculares à parte aérea da planta, reduzindo a sua expansão. Davies et al. (1986) encontraram em seus trabal hos queas raízes próximas da superfície do solo foram as mais afetadas pelo déficit hídrico. 
Quadro 2. Resultados do quadrado médio da lâmi na total de água armazenada no solo, lâmina de água disponível às plantas no perfil (CADatual), fração de água disponível e evapotranspiração real durante o ciclo da cultura do milho, sob dois níveis de manejo de água, em três solos de diferentes texturas

\begin{tabular}{|c|c|c|c|c|c|c|c|c|}
\hline \multirow{2}{*}{$\begin{array}{l}\text { Causa da } \\
\text { variação }\end{array}$} & \multicolumn{8}{|c|}{ Dias após a emergência } \\
\hline & 15 & 17 & 20 & 22 & 24 & 27 & 29 & 31 \\
\hline & \multicolumn{8}{|c|}{ Quantidade total de água armazenada no solo (QTA) } \\
\hline $\begin{array}{l}\text { Texturas (T) } \\
\text { Níveis (N) } \\
T \times N \\
\text { Resíduo }\end{array}$ & $\begin{array}{c}13.356,25^{*} \\
0,0100^{\text {ns }} \\
89,120^{\text {ns }} \\
98,56\end{array}$ & $\begin{array}{c}13.712,54^{*} \\
0,01000^{\mathrm{ns}} \\
115,080^{\mathrm{ns}} \\
107,88\end{array}$ & $\begin{array}{c}14.069,28 * \\
64,8600^{\text {ns }} \\
77,2700^{\text {ns }} \\
109,57\end{array}$ & $\begin{array}{c}15.318,33^{*} \\
375,980^{\mathrm{ns}} \\
45,1100^{\mathrm{ns}} \\
73,78\end{array}$ & $\begin{array}{c}14.642,27^{*} \\
288,800^{\mathrm{ns}} \\
45,4600^{\mathrm{ns}} \\
94,99\end{array}$ & $\begin{array}{c}15.101,27^{*} \\
472,000^{\mathrm{ns}} \\
32,9600^{\mathrm{ns}} \\
103,61\end{array}$ & $\begin{array}{c}15.234,76 * \\
823,5200^{*} \\
25,5300^{\text {ns }} \\
96,41\end{array}$ & $\begin{array}{c}14.406,82^{*} \\
1.666,160^{*} \\
50,8700^{\text {ns }} \\
78,51\end{array}$ \\
\hline \multirow[t]{2}{*}{ C.V. (\%) } & 5,62 & 5,90 & 5,99 & 5,00 & 5,61 & 5,99 & 5,83 & 5,25 \\
\hline & \multicolumn{8}{|c|}{ Capacidade de armazenamento de água disponível às plantas (CAD atual) } \\
\hline $\begin{array}{l}\text { Texturas (T) } \\
\text { Níveis (N) } \\
T \times N \\
\text { Resíduo }\end{array}$ & $\begin{array}{c}9,05^{\text {ns }} \\
59,57^{\text {ns }} \\
3,990^{\text {ns }} \\
249,97\end{array}$ & $\begin{array}{c}129,65^{\text {ns }} \\
0,0100^{\text {ns }} \\
114,87^{\text {ns }} \\
248,64\end{array}$ & $\begin{array}{c}185,29^{\mathrm{ns}} \\
45,880^{\mathrm{ns}} \\
45,310^{\mathrm{ns}} \\
176,02\end{array}$ & $\begin{array}{c}196,12^{\text {ns }} \\
261,66^{\text {ns }} \\
25,150^{\text {ns }} \\
170,44\end{array}$ & $\begin{array}{c}232,96^{\text {ns }} \\
376,10^{\text {ns }} \\
45,060^{\text {ns }} \\
176,05\end{array}$ & $\begin{array}{c}441,64^{\mathrm{ns}} \\
500,86^{\mathrm{ns}} \\
25,240^{\mathrm{ns}} \\
167,54\end{array}$ & $\begin{array}{c}525,12^{\text {ns }} \\
941,75^{*} \\
26,380^{\text {ns }} \\
134,19\end{array}$ & $\begin{array}{c}286,99^{\text {ns }} \\
1595,52^{*} \\
52,440^{\text {ns }} \\
159,93\end{array}$ \\
\hline \multirow[t]{2}{*}{ C.V. (\%) } & 21,515 & 21,02 & 17,83 & 17,67 & 18,72 & 18,27 & 16,50 & 18,77 \\
\hline & \multicolumn{8}{|c|}{ Fração de água disponível (FAD) } \\
\hline $\begin{array}{l}\text { Texturas (T) } \\
\text { Níveis (N) } \\
T \times N \\
\text { Resíduo }\end{array}$ & $\begin{array}{l}0,0490^{*} \\
0,0003^{\mathrm{ns}} \\
0,0106^{\mathrm{ns}} \\
0,006\end{array}$ & $\begin{array}{l}0,0550^{*} \\
0,0007^{\text {ns }} \\
0,0140^{\text {ns }} \\
0,007\end{array}$ & $\begin{array}{l}0,0630^{*} \\
0,0061^{\text {ns }} \\
0,0107^{\text {ns }} \\
0,007\end{array}$ & $\begin{array}{l}0,0650^{*} \\
0,0280^{\text {ns }} \\
0,0083^{\text {ns }} \\
0,006\end{array}$ & $\begin{array}{l}0,0790^{*} \\
0,0370^{\text {ns }} \\
0,0077^{\text {ns }} \\
0,005\end{array}$ & $\begin{array}{l}0,0840^{*} \\
0,0430^{\text {ns }} \\
0,0057^{\text {ns }} \\
0,006\end{array}$ & $\begin{array}{l}0,0820^{*} \\
0,0780^{\text {ns }} \\
0,0036^{\text {ns }} \\
0,0059\end{array}$ & $\begin{array}{l}0,0820 * \\
0,1540 * \\
0,0034^{\text {ns }} \\
0,0042\end{array}$ \\
\hline \multirow[t]{2}{*}{ C.V. (\%) } & 10,97 & 11,60 & 11,77 & 10,92 & 10,27 & 12,24 & 11,61 & 9,81 \\
\hline & \multicolumn{8}{|c|}{ E vapotranspiração da cultura (ETr) } \\
\hline $\begin{array}{l}\text { Texturas (T) } \\
\text { Níveis (N) } \\
T \times N \\
\text { Resíduo }\end{array}$ & $\begin{array}{c}13,05^{\text {ns }} \\
15,32^{\text {ns }} \\
2,030^{\text {ns }} \\
4,02\end{array}$ & $\begin{array}{l}2,44^{\mathrm{ns}} \\
0,01^{\mathrm{ns}} \\
4,07^{\mathrm{ns}} \\
2,90\end{array}$ & $\begin{array}{c}4,520^{\text {ns }} \\
261,57^{*} \\
3,860^{\text {ns }} \\
5,19\end{array}$ & $\begin{array}{c}8,410^{\mathrm{ns}} \\
77,42^{*} \\
5,320^{\mathrm{ns}} \\
2,61\end{array}$ & $\begin{array}{c}10,71^{\mathrm{ns}} \\
42,15^{*} \\
0,800^{\mathrm{ns}} \\
3,31\end{array}$ & $\begin{array}{c}1,010^{\mathrm{ns}} \\
521,13^{*} \\
5,230^{\mathrm{ns}} \\
8,70\end{array}$ & $\begin{array}{c}3,940^{\text {ns }} \\
51,54^{*} \\
8,260^{\text {ns }} \\
8,07\end{array}$ & $\begin{array}{c}9,910^{\mathrm{ns}} \\
170,17^{\mathrm{n}} \\
9,510^{\mathrm{ns}} \\
3,34\end{array}$ \\
\hline C.V. (\%) & 49,81 & 55,02 & 16,48 & 26,62 & 39,95 & 31,63 & 52,58 & 25,56 \\
\hline
\end{tabular}

T x N : interação textura do solo X níveis de manejo da água no solo. * significativo pelo teste $\mathrm{F}(\mathrm{P} \leq 0,05)$. ${ }^{\mathrm{ns}}$ não-significativo.

As plantas de milho retiraram quase a totalidade da água disponível no solo detextura franco-arenosa atéaproximadamente 45 dias após o início do déficit (60 DAE, Figuras 1 e2), além de apresentarem taxa de extração relativamente constante nas três camadas do solo. Esse comportamento possibilitou às plantas de milho completarem o seu desenvolvimento vegetativo, além de acumularem reservas de fotoassimilados suficientes para propiciar rendimento de grãos, mesmo em condi ções severas de déficit hídrico. Esses resultados evidenciam que no solo de textura franco-arenosa não ocorreu secamento rápido da camada superficial do solo, evitando, com isso, a inviabilização de parte do sistema radicular, confinado nesta camada, minimizando o envio de sinais radiculares para a parte aérea da planta. Davies et al. (1990) e Ball et al. (1994) demonstraram que o mais rápido secamento da camada superficial do solo provocou aumento na concentração de ácido abscíssico nas plantas, provocando o fechamento estomático e a diminuição da expansão foliar.
No sol o detextura franco-argil o-siltosa, o período de extração de água no solo foi maior nas camadas de $0-20$ e $20-40 \mathrm{~cm}$ de profundidade do que o observado nos solos de textura franco-arenosa e argila pesada (Figuras 1 e 2), mesmo apresentando menor CAD no solo (Quadro 1). No entanto, esta menor taxa de extração, embora tenha sidovantajosa para as plantas submeti das a défi cit hídrico, limitou a expansão inicial do dossel vegetativo das plantas, uma vez que o crescimento não pode ser recuperado se o déficit hídrico for interrompido por um regime pluviométrico favorável, pois a cultura do milho apresenta hábito de crescimento determinado.

Diferenças na evapotranspiração da cultura entre os níveis de manejo da água de irrigação foram observadas aos 20 DAE (5 dias após a aplicação do déficit hídricoterminal) com menor evapotranspiração para os tratamentos submetidos a déficit hídrico (Quadro 2). Os val ores médi os da evapotranspiração da cultura ao longo do ciclo de crescimento e desenvolvimento das plantas foram de 3,25, 3,01 e $3,31 \mathrm{~mm}^{\text {dia-1 }}{ }^{-1}$ para as plantas mantidas sob irrigação, 


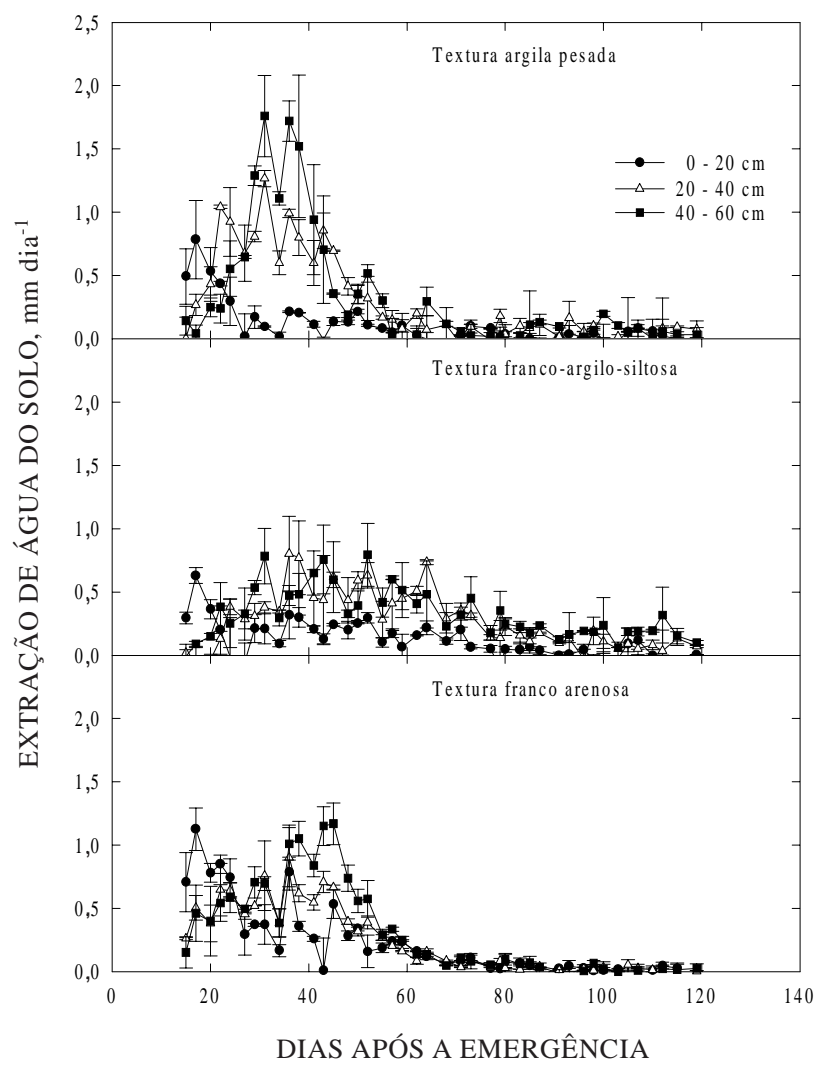

Figura 1. Valores da taxa de extração média diária de água no solo pelas plantas de milho submetidas a déficit hídrico terminal em cada profundidade do solo em três solos de diferentes texturas. As barras verticais representam o desvio-padrão.

ede $0,74,0,75$ e $0,76 \mathrm{~mm}$ dia-1, para as plantas submetidas a déficit hídricoterminal para os sol os detextura argila pesada, franco-argilo-siltosa efranco-arenosa, respectivamente(Figura 3). Esses resultados evidenciam que, mesmo em condições de irrigação, ocorreu maior evapotranspiração da cultura (evapotranspiração máxima) para as plantas demil ho cultivadas em solo de textura franco-arenosa. Os valores médios de evapotranspiração da cultura, em condições de déficit hídrico, representam unicamente a contribuição da água armazenada no solo disponível às plantas. Os valores da evapotrans-piração acumulada total de água do sol o pelas plantas irrigadas foram de 342,4, 322,8 e $352,8 \mathrm{~mm}$, para os sol os argila pesada, francoargilo-siltosa e franco-arenosa, respectivamente.

No período de 20 a 40 DAE, os val ores médi os da evapotranspiração da cultura foram de 1,97, 0,96 e $1,81 \mathrm{~mm}$ dia-1, para as plantas de mil ho submetidas a déficit hídrico terminal nos solos de textura argila pesada, franco-argilo-siltosa e franco-arenosa, respectivamente. A evapotranspiração da cultura foi

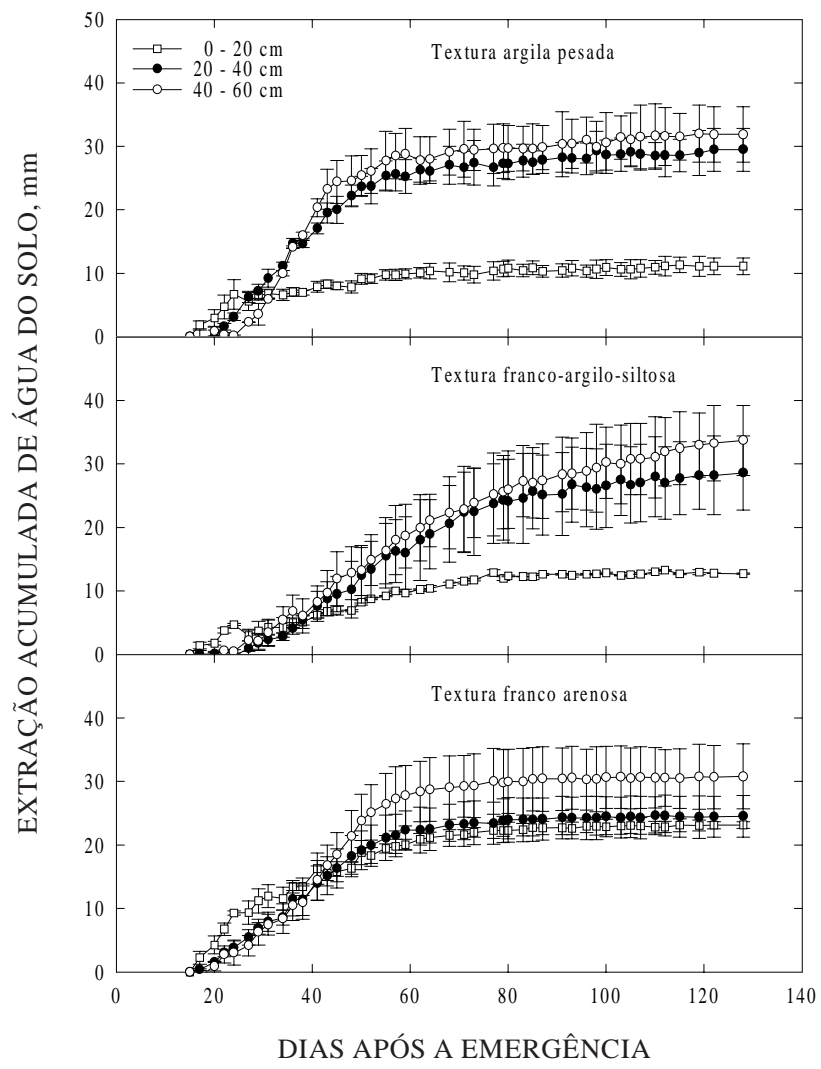

Figura 2. Variação dos valores médios da extração acumulada de água pelas plantas de milho submetidas a déficit hídrico terminal em cada profundidade do solo em três solos de diferentes texturas. As barras verticais representam o desvio-padrão.

mai or para as plantas cultivadas em sol o de textura argila pesada do que nas outras classes de texturas após a aplicação do déficit. Isto indica que, neste solo, por causa da maior quantidade total de água armazenada no perfil do solo, as plantas de milho possivelmente não acionaram mecanismos de adaptação a condições de déficit hídrico no solo, utilizando praticamente toda a água disponível no solo para a expansão do dossel vegetativo sem reduzir drasticamente o consumo de água. Um elevado dossel vegetativo em situações de déficit hídrico terminal é um aspecto negativo pelo fato de praticamente toda a água disponível armazenada no solo ser utilizada pelas plantas para minimizar os efeitos letais da elevação da temperatura do dossel, devidos à absorção da radiação sol ar. Por outro lado, este aspecto é vantajoso em situações de déficit hídrico intermitente, caso em que a manutenção de um elevado dossel vegetativo é positiva após a interrupção do déficit hídrico, considerando a maior área do dossel fotossinteticamente ativa, com aumento no potencial produtivo da cultura. 


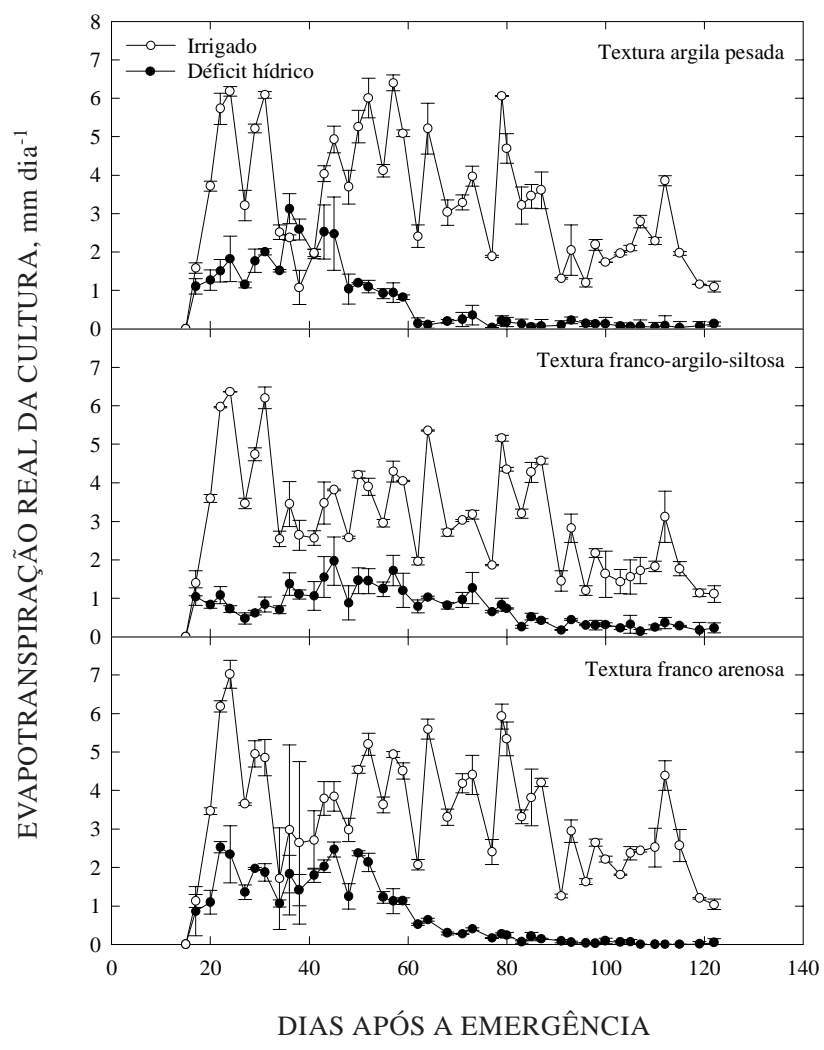

Figura 3. Evapotranspi ração média da cultura do milho submetida a dois manejos da água de irrigação (irrigado e déficit hídrico terminal) em em três solos de diferentes texturas. As barras verticais representam o desvio-padrão.

\section{CONCLUSÕES}

1. Para uma mesma profundidade do solo e em condições de déficit hídrico, o sol o de textura francoarenosa apresenta maior capacidade de armazenamento de água disponível às plantas de milho.

2. O maior armazenamento total deágua no perfil de solos de textura argila pesada e franco-argilosiltosa não representou maior disponibilidade de água às plantas de milho.

\section{LITERATURA CITADA}

ANGUS, J .F.; HASE GAWA, T C. \& HSAIO, S.P.The water balance of pos-monsoonal dryland crops. J. Agric. Sci., 101:699-710, 1983.

BALL, R.A.; OOSTERHUIS, D.M. \& MAUROMOUSTAKOS, A. Growth dynamics of the cotton plant during water-deficit stress. Agron. J ., 86:788-795, 1994.
BEGG, J.E. \& TURNER, N.C. Crop water deficits. Adv. Agron., 28:161-217, 1976

BLUM, A.; J OHNSON, J.W. \& RAMSEUR, E.L. The effect of a drying top soil and a possible non-hydraulic root signal on whear growth and yield. J . Exp. Bot., 42:1225-1231, 1991.

CARLESSO, R. Absorção de água pelas plantas: água disponível versus extraível e a produtividade das culturas. Ci. Rural, 25:183-188, 1995.

CARLESSO,R. Influence of soil water deficits on maize growth and leaf area adjustments. East Lansing, Michigan State University. 1993.275p. (Tese de Doutorado)

CIRILO, A.G. \& ANDRADE, F.H. Sowing date and maize productivity: I. Crop growth and dry matter partitioning. Crop Sci., 34:1039-1043, 1994.

DAVIES, W.J .; METCALFE, J . \& LODGE, T.A. Plant growth substances and the regulation of growth undedrought. Aust. J. Plant Physiol., 13:105-125, 1986.

DAVIES,W.J .; MANSFIELD,T.A. \& HETHERINGTON, A.M. Sensing of soil water status and the regulation of plant growth and development. Plant Cell Environ., 13:709-719, 1990.

DENMEAD, O.T. \& SHAW, R.H. Availability of soil water to plants as affected by moisture content and meteorological conditions. Agron. J ., 54:385-390, 1962.

FIORIN, J.E.; ALBUQUERQUE, J.A. \& REINERT, D.J . Produtividade do milho induzida pela variação de armazenamento de água em um Podzólico VermelhoAmarelo. In: CONGRESSO BRASILEIRO DE ENGENHARIA AGRÍCOLA, 21, SIMPÓSIO DE ENGENHARIA AGRÍCOLA DO CONE SUL, 1., Santa Maria, 27-31 jul. 1992. Anais. Santa Maria: Sociedade Brasileira de Engenharia Agrícola, 1992. v. 2B. p.951-962.

FISCHER, R.A. \& TURNER, N.C. Plant productivity in the arid and semi-arid zones. Ann. Rev. Plant Physiol., 29:277-317, 1978.

HOOGENBOOM, G.; HUCK, M.G. \& PETERSON C.M. Root growth rate of soybean as affected by drought stress. Agron. J., 79:697-704, 1987.

HSIAO, T.C. Plant response to water stress. Ann. Rev. Plant Physiol., 24:519-570, 1973.

HURD, E.A. Phenotype and drought tolerance in wheat. Agric. Meteorol., 14:39-55, 1974.

KIEHL, E.J . Manual de edafologia. São Paulo, CERES, 1979. 215p.

KRIEG, D.R. Sorghum. I n:TEARE, I.D. \& PEET, M.M., eds. Crop water relations. New York, J ohn Willey \& Sons, 1983. p.351388.

LUDLOW, M.M. \& MUCHOW, R.C. A critical evaluation of trits for improving crop yields in water-limited environments. Adv. Agron., 43:107-153, 1990.

MATZENAUER, R. \& SUTILI, R. A água na cultura do milho. IPAGRO I nforma, 26:17-32, 1983.

MEYER, W.S. \& GREEN, G.C. Water use by wheat and plant indicator of available soil water. Agron. . ., 72:253-257, 1980.

PASSIOURA, J.B. Root and drought resistense. In: STONE, J S. $\&$ WILLIS, W.O. eds. Plant production and management under drought conditions. Amsterdan. Agric. Water Manag. Elsevier, 1983. p.265-280. 
PEACOAK, J.M. \& WILSON, G.L. Sorghum. In: GOLDSWORTHY, P.R. \& FISCHER, N.M. eds. The physiology of tropical field crops. New York, Willey, 1984. p.249-279.

RITCHIE, J.T. Water dynamics in the soil-plant-atmosphere system. Plant Soil, 58:81-96, 1981.
RITCHIE, J.T.; BURNETT, E. \& HENDERSON, R.C. Dryland evaporative flux in a subhumid climate. 3. Soil water influences. Agron. J ., 64:168-173, 1972.

WILSON, G.L. \& EASTIN, J.D. The plant and its environment. In: WILSON, G.L. \& EASTIN, J.D. Sorghum in the Eighties, ICRISAT, 1982. v.1. p.101-119, 1982. 